Research, Society and Development, v. 9, n. 3, e103932666, 2020

(CC BY 4.0) | ISSN 2525-3409 | DOI: http://dx.doi.org/10.33448/rsd-v9i3.2666

\title{
Meditação da Técnica e A Guerra do Fogo: algumas considerações e aproximações
}

Technical Meditation and The Fire War: some considerations and approaches

Meditación Tecnica y Guerra de Fuego: algunas consideraciones y enfoques

Recebido: 24/01/2020 | Revisado: 09/02/2019 | Aceito: 14/02/2020 | Publicado: 20/02/2020

\section{Eduardo dos Santos de Oliveira Braga}

ORCID: https://orcid.org/0000-0002-8742-6981

Instituto Federal de Educação, Ciência e Tecnologia do Rio de Janeiro, Brasil

E-mail: eduardo.braga@ifrj.edu.br

Valéria da Silva Lima

ORCID: https://orcid.org/0000-0002-9468-8664

Instituto Federal de Educação, Ciência e Tecnologia do Rio de Janeiro, Brasil

E-mail: valeriaslima8910@yahoo.com.br

\section{Resumo}

No presente texto apresentamos uma resenha do livro Meditação da Técnica, de Ortega y Gasset que, em 1963, decidiu publicar suas notas de aula de um curso que o autor ministrou sobre o assunto na Universidade Internacional de Verão de Santander. Utilizamos também o filme A guerra do fogo, de 1981, dirigido por Jean-Jacques Annaud, como fio condutor de aproximações e reflexões a respeito do livro em questão.

Palavras-chave: Técnica; Estágios da técnica; Fogo.

\begin{abstract}
In this text we present a review of the book Meditação da Técnica, by Ortega y Gasset who, in 1963, decided to publish his class notes of a course that the author taught on the subject at the International University of Summer of Santander. We also used the 1981 film The War of Fire, directed by Jean-Jacques Annaud, as the guiding thread of approximations and reflections about the book in question.
\end{abstract}

Keywords: Technique; Technique stages; Fire.

\section{Resumen}

En este texto presentamos una revisión del libro Meditação da Técnica, de Ortega y Gasset, quien, en 1963, decidió publicar sus notas de clase de un curso que el autor impartió sobre el 
tema en la Universidad Internacional de Verano de Santander. También utilizamos la película de 1981 La guerra del fuego, dirigida por Jean-Jacques Annaud, como hilo conductor de aproximaciones y reflexiones sobre el libro en cuestión.

Palabras clave: Tecnica; Etapas de la tecnica; Fuego.

\section{Apresentação inicial}

Este trabalho apresenta uma resenha a respeito do livro de Ortega y Gasset, de 1963, intitulado por Meditação da Técnica. O livro apresenta notas feitas às pressas para um curso desenvolvido no ano de 1933, na Universidade Internacional de Verão de Santander, na Espanha, cujo título é o nome do curso ofertado no ano de inauguração da referida Universidade: Meditação da Técnica. Nele, o autor traz profundas reflexões a respeito do que vem a ser técnica e a sua relação com o homem.

Além do livro supracitado, utilizamos para interagir com as notas apresentadas pelo livro o filme A guerra do fogo, de 1981, dirigido por Jean-Jacques Annaud, com roteiro de Gérard Brach baseado no romance La Guerre $d u$ feu, de J.-H. Rosny aîné. O filme traz questões reflexivas a respeito do domínio da técnica e das tecnologias nas relações de poder. Com sons e linguagem embrionária, a trama se desenrola a partir da descoberta do fogo e das relações que a mesma apresenta as diferentes tribos representadas no decorrer da história. Vislumbramos nessa obra uma possibilidade de aproximação de reflexões e discussões com os assuntos que são apresentados pelo livro.

\section{A resenha e a aproximação com o filme A guerra do fogo}

De acordo com Ortega y Gasset (2009), a missão do escritor é prever para seus leitores o que um dia será um problema, o texto - que, na verdade, são notas realizadas pelos autores para o curso Meditação da Técnica - procura resposta para o que é Técnica. Uma primeira tentativa de ataque se fundamenta na relação inverno e homem, mais especificamente no ato de o homem encontrar essa realidade que é sentir frio e no fato de essa realidade se apresentar como uma agressão, com caráter negativo, ao homem. Isso se dá, pois o homem prefere viver e o sentir frio vem como uma morte para ele. Essa preferência pela vida é tão intrínseca que nos soa absurda a indagação do por que o homem prefere viver. $\mathrm{O}$ instinto de conservação não responde ao questionamento, dado que a ideia trazida pela palavra instinto não é clara; e, 
mesmo se fosse, o homem não vive de instinto, uma vez que ele reflete e tem vontades. Independentemente das justificativas, sabe-se que o homem sobrevive porque quer.

Por conta dessa vontade de viver, quando o homem é ameaçado pelo frio ele sente a necessidade de proporcionar a si mesmo calor. Em meio a uma tempestade de inverno, um relâmpago acende um fogo, cujo homem, dotado do poder de caminhar, desloca-se até próximo à chama para se esquentar. Observa-se que o homem se aquece fazendo uso de um calor que já está disponível a ele. Nota-se também que, no filme A guerra do fogo (1981), um grupo de primitivos faz uso do fogo para, dentre outras utilidades, esquentar-se. Porém, eles não dominavam a sua produção. $\mathrm{E}$, numa batalha contra outro grupo, acabam perdendo a chama que mantinham acessa. A partir daí, o filme mostra as batalhas que dois integrantes desse grupo tiveram que enfrentar a fim de recuperarem o fogo. Enquanto não o tinha de volta, o grupo se refugiava em cavernas, denotando que o calor não provém apenas do fogo.

Além do esquentar-se, o alimentar-se e o caminhar são exemplos de algumas outras necessidades do homem. Naturalmente que elas são necessárias para que o homem viva. Mas, importa aqui repararmos na significação que tem necessidade. Nesse sentido, tal necessidade é condicionada à vida. $\mathrm{O}$ alimentar-se, por exemplo, é necessário para viver. Então, o viver se apresenta como a necessidade originária e as demais necessidades são consequências dela. Denota-se, portanto, um sentido subjetivo para necessidade, uma vez que a decisão por viver vem, autocraticamente, da vontade do homem. E essa vontade é tão latente que, conforme mostra o filme A guerra do fogo, apesar da natureza ter proporcionado ao grupo o fogo, na sua perda, eles tentam recupera-lo. Nessa busca, encontram um novo grupo que dominava a produção do fogo e, a partir da observação, reproduz o ato de fazer fogo. Atente-se que quando a natureza (o que está ao redor do homem) não oferta ao homem suas necessidades para satisfazer à vida - necessidades comuns aos homens e animais, ele mesmo faz o fogo, faz a caça, a agricultura, os automóveis e os edifícios. Isso o difere dos animais, uma vez que o homem tem dotes intelectuais que o faz defender sua vida.

Não é falta de inteligência que diferencia o homem do animal, mas a capacidade que o homem tem em se desgarrar das urgências vitais para se ocupar com atividades que não são satisfação de necessidades, como a fabricação de carro, a agricultura e o aquecimento. O animal está sempre agarrado à satisfação de suas necessidades orgânicas e biológicas e aos atos que as satisfazem. Ele não pode sair da natureza e nem pode se retirar do seu repertório de atos naturais. Já isso não é a circunstância do homem, posto que ele pode voltar-se para 
dentro de si e se ocupar com invenções como fazer fogo e montar um automóvel. Nesse sentido, falar de necessidades, com a mesma ideia que atribuímos ao homem, não faz sentido para os animais. Uma vez que a vida do homem não coincide com suas necessidades orgânicas, o que ocorre com os animais. Se coincidisse, comer, beber e esquentar-se, por exemplo, não seria sentido pelo homem como necessidade. E, consequentemente, não teria que se ocupar em satisfazê-las. Cabe destacar, porém, que o animal tem necessidades no sentido subjetivo que atribuímos ao homem.

Todas estas intervenções praticadas pelo homem desencadeiam invenções de procedimentos de coisas que não existem na natureza (ou que existem, mas não estão disponíveis no momento), mas que necessitamos. O domínio da produção do fogo por um dos grupos do filme A guerra do fogo mostra que, com elementos da natureza, os homens primitivos fizeram o fogo. Essas imposições da natureza ao homem faz com que ele exerça mudanças nela, adaptando as suas necessidades a natureza. Isso leva a criar entre ambos uma nova natureza posta sobre a anterior, uma sobre natureza. Denota-se, portanto, que atos como o citado acima referente ao filme modificam a natureza ou circunstância, em vista da satisfação das necessidades do homem. Chamamos tais atitudes de atos técnicos do homem. $\mathrm{O}$ conjunto desses atos é denominado, portanto, por Técnica. Cabe destacar ainda que a técnica não é o que faz o homem para satisfazer suas necessidades. Ao se sentir necessitado, o homem reforma a natureza, deixando de ser uma angústia sua satisfação e anulando, assim, quando possível, suas necessidades. Sendo assim, a Técnica é a adaptação do meio ao sujeito e não o inverso.

A reação do homem contra o meio é o que o caracteriza como homem. Essa reação, até então, é concernente à satisfação das necessidades biológicas ou orgânicas. Porém, não se limita a isso. Tão antigo quanto à satisfação dessas necessidades, temos outras, como a embriaguez, cuja finalidade proporciona ao homem situações desnecessárias nesse sentido. Inclusive, não se sabe se o fogo foi inventado com o objetivo primeiro de aquecer-se ou para embriagar-se. O que importa é que se infere de tal fato que os primitivos atribuíam importância não apenas às necessidades mínimas para viver, mas também, as necessidades para se proporcionar certos estados prazerosos. Por isso, de forma indiferente, o conceito de necessidade humana inclui tanto o objetivamente necessário quanto o supérfluo. Nota-se, ainda, que separar o inevitável do supérfluo é tarefa difícil. Por vezes, adaptamo-nos a incrível redução de alimentos ou mesmo a intensidades altas de frio, mas, ao mesmo tempo, não conseguimos dispensar certas coisas supérfluas. Extrai-se daí que é inseparável o desejo do 
homem por viver (estar) e por estar bem (bem-estar). E é esse bem-estar que faz com que ele sinta como necessidade as condições objetivas do estar. Suicida-se o homem que não consegue ao menos uma aproximação para o que ele chama de bem-estar. Torna-se, assim, o bem-estar a necessidade das necessidades do homem. Nota-se que antes a necessidade originária era o viver, enquanto que agora chegamos a um conceito distinto a respeito das necessidades humanas. Seu empenho é em estar bem e o supérfluo é necessário para isso. Todas as outras necessidades canalizam para o bem-estar do homem.

O entendimento do supérfluo enquanto necessidade humana é importante para entendermos a técnica. Pois, tanto hoje quanto na época paleolítica, a técnica é a produção do supérfluo. Aqui está mais um fato que caracteriza o animal como atécnico: ele se contenta com o simples existir - adaptação do sujeito ao meio. Enquanto que para o homem existir, pressupõe bem-estar - adaptação do meio ao sujeito. Ou seja, não há homem sem técnica. Assim, homem, técnica e bem-estar são sinônimos. Com esta relação intrínseca entre necessidades humanas e bem-estar, somente poderemos constatar quais são aquelas se nos certificarmos antes o que é bem-estar para o homem. Tarefa esta muito complicada, dado que bem-estar é um termo variável, diferentemente, do simples viver, no sentido biológico. Como as necessidades humanas estão em função do bem-estar, resulta que elas também são mutáveis. E, como a técnica é sinônimo de bem-estar, ela também tem uma realidade variável e, por isso, não pode ser estudada de maneira independente e nem se pode atribuir a ela a ideia de progresso.

Com o bem-estar sendo a necessidade das necessidades, os atos técnicos são aqueles em que há dedicação de esforço para inventar e executar um plano de atividade que nos permita assegurar a satisfação das necessidades elementares, atribuindo o mínimo de esforço a essa satisfação e possibilitando a criação de objetos que não existem na natureza do homem. O esforço para poupar esforço é o que é a técnica. Ou seja, a técnica é um esforço menor para evitarmos um esforço maior que determinada circunstância primariamente nos impõe. E é esse poupar esforço que inspira a técnica. Nesse contexto, inculca-nos compreender em que se ocupará a vida do homem, se, com o fazer técnico ele economiza esforço e se isenta das canseiras impostas pela natureza. Não fazer nada não condiz com o homem, uma vez que isso é sinônimo de não viver. Conclui-se que o homem para não ter que fazer o que faz o animal (tudo o que é preciso fazer para sustentar-se na vida), dedica-se a tarefas não biológicas que ele inventa para si mesmo. E é essa vida inventada e, portanto mutável, que o homem chama de bem-estar. Sendo assim, a vida humana ultrapassa a realidade natural. 
Há uma superficialidade muito grande nas respostas dadas para o que é técnica. É preciso se aprofundar no surgimento do propriamente humano, para tentar conter a superficialidade que é compartilhada pelas questões que se referem ao humano no homem. Por esse ângulo, percebe-se que no universo acontece o seguinte fato: se quer existir, o homem se vê obrigado a estar em outro ente, o mundo ou a natureza. Para isso: a natureza poderia oferecer ao homem total facilidade para sua permanência nela; a natureza poderia ofertar ao homem somente dificuldades; ou, então, a natureza poderia dispor ao homem tanto facilidades, quanto dificuldades para sua permanência nela. No primeiro caso, o homem seria um ser natural, como acontece com as plantas e as pedras. Não teria nenhum desejo em que a natureza não pudesse lhe proporcionar. No segundo caso, o homem e a natureza seriam seres antagônicos e de não convivência. Assim, não haveria vida humana e nem técnica. Já o terceiro caso é o que, de fato, ocorre. O ser do homem e o ser da natureza não coincidem plenamente. Aqui o existir está cercado de facilidades e dificuldades que juntos proporcionam um caráter ontológico à vida humana. São as facilidades encontradas no mundo que apoiam a possibilidade de existência do homem. Já as dificuldades colocam em perigo tal possibilidade, exigindo dele não passividade na luta pelo seu alojamento no mundo.

Constata-se, então, que o homem tem que ganhar a vida por si mesmo, fazendo em cada momento sua existência. Por hora, parte dele se mostra afim com a natureza. Mas, em outros momentos não. Isso é ao mesmo tempo natural e extranatural. $\mathrm{O}$ que tem de natural não lhe é problema e, por isso, o homem não sente como seu autêntico ser. Porém, como o extranatural consiste numa pretensão de ser - projeto de vida - o mesmo não é realizado. E é isso que sentimos como nosso verdadeiro ser, nossa personalidade. Nesse sentido, a vida seria o desejo de se realizar um projeto, onde nosso eu é o programa imaginário dessa pretensão. Consequentemente, o homem é o que aspira ser, sem realidade corporal e espiritual. Ou seja, um ser que consiste em ainda não ser. E isso é condição do ser humano que o diferencia de todas as outras coisas que compõe o universo. Cabe enfatizar que coisas aqui significa todo ser que consiste em ser o que já é, coincidindo sua potencialidade com sua realidade. Corpo e alma são exemplos de coisas. Como o homem não é uma coisa, mas sim uma pretensão de ser, o corpo e a alma não são o homem, mas este faz uso daqueles para viver. Pode-se, então, dizer que natureza, mundo ou circunstância é o sistema de facilidades e dificuldades em que o homem programático se encontra. E somente em função da pretensão do homem que temos em alguma coisa facilidade ou dificuldade. Assim explica o fato do mundo ser distinto para cada homem. Além disso, como o ser do homem é pura possibilidade imaginária, destaca-se o 
fato dos homens serem desiguais e da espécie humana ser de uma variabilidade incomparável com as espécies de animais.

\subsection{A existência do homem}

A existência do homem não é pronta e acabada, mas sim ele tem que fazer sua existência. É a possibilidade de ser e a busca para realizar tal projeto. Diferente de todos os seres, o homem ao existir se ocupa em executar o programa imaginário em que consiste. Pois, nos demais seres supõe a atuação de alguém ou de alguma coisa que já é. Já o homem precisa atuar, autofabricar-se para ser. E essa autofabricação pressupõe que o homem, na raiz de sua essência, encontra-se na situação do técnico. O homem para viver aproveita o que tem para obter o que ainda não tem. Isso é produção, o que desmistifica o fato de que a vida é contemplação, pensamento e teoria, conforme se considerava por muitos séculos. Na verdade, a vida é produção, fabricação. E por exigência disso, posteriormente é pensamento, teoria e ciência. Nesse sentido, o mundo se apresenta como possível máquina para o homem no ato de viver. O homem tem uma tarefa extranatural, não podendo dedicar suas energias para satisfazer suas necessidades elementares, como fazem os animais, mas deve trabalhar no sentido de realizar seu ser no mundo. Denota-se, portanto, que o homem começa quando também se começa a técnica, cuja primeira missão é atribuir privilégio ao homem para que ele se dedique a ser ele mesmo.

A existência humana ocorre através da obrigação de unificação entre dois entes heterogêneos - o mundo e o homem, cujo homem tenta inserir no mundo seu ser extramundano. E, é nessa combinação entre os dois entes que se tem a técnica. O homem precisa agir com o objetivo de obter segurança em seu confronto com as exigências naturais, dominando-as com o máximo de rendimento e não dissipando seu esforço. Se não precisássemos se valer da natureza para alcançarmos a pretensão extranatural que é do homem, as técnicas não existiriam. Note que a pretensão de vida do homem é pré-técnico, já as técnicas são as concreções de autofabricação próprio de nosso viver, que também são uma invenção. Essa pretensão, esse desejo referente a coisas se direcionam sempre dentro do perfil do homem que queremos ser, sendo este, portanto, a fonte de todos os outros desejos. A plenitude desse plano vital é o bem-estar do homem. Ortega ressalta aqui a dificuldade de seu tempo, a saber: o homem não deseja a si mesmo - desejo fundamental - e, assim, possui senão falsos desejos. A crise dos desejos coloca toda a técnica como algo inservível, uma vez que não é a técnica que faz nascer esse desejo. E isso é grave: a Europa sofre de uma 
debilidade em sua faculdade de desejar, o que traz um retrocesso para a técnica. Frente ao grande repertório que se apresenta ao homem de hoje para viver, falta-lhe imaginação para saber o que ser e inventar o argumento de sua própria vida.

Alguns exemplos são trazidos à tona exemplificando os muitos programas vitais em que o homem historicamente concretou em seu ser. Dentre eles, o bodhisatva hindu e o gentleman de 1850 na Inglaterra. Destaca-se, inclusive, que as técnicas criadas por estes não são iguais. Ser bodhisatva é ser a negação vivente da natureza. E isto requer que a natureza se adapte, deixando um espaço para uma qualidade de ser que é tão antagônica a ela. A explicação naturalista do humano sustentará aqui que a relação existente entre o projeto de ser e a técnica é inversa ao que Ortega propõe: que é o projeto quem suscita a técnica, reformando a natureza. Para justificar isso, utiliza-se, como exemplo, que a arquitetura do Estado Tibetano é a expressão do budismo nascido nas planícies da Índia, cujo aspecto natural é bem distinto do Tibet. Foi o budismo quem interferiu na arquitetura Tibetana e não o clima. Caso fosse o clima e a terra, não se explicaria a religião budista no Tibet, uma vez que ela provém da terra da Índia e do seu clima. O budismo é essencialmente o trabalho da meditação. E para meditar na cruel tempérie tibetana foi necessário construir conventos de pedras e sal - primeiros edifícios a surgir por lá. Não só a finalidade de moradia tem a casa em Tibet, mas também para orar. Nota-se como um artefato planejado para determinada finalidade se desloca para outras utilizações.

Já sabemos que as técnicas criadas pelo bodhisatva e pelo gentleman não são as mesmas. Sabemos também que existência para bodhisatva é ser a negação vivente da natureza. Não é pautada no individualismo, mas a verdadeira existência para ele é fundir-se no todo e desaparecer nele. Mas, o que é ser gentleman? Pode-se dizer que o gentleman é o oposto do bodhisatva, pois ele quer viver com intensidade neste mundo e ser o mais independente - indivíduo - que possa. O gentleman não é intelectual e faz de sua existência um jogo, cujo objetivo é ser um bom jogador na mais rude realidade do mundo. Sabe que a vida é difícil e, por isso, ocupa-se em ter o domínio sobre a circunstância e sobre o homem. Destaca-se que é preciso ir pensando em um tipo de gentleman que seja compatível com a pobreza que ameaça o planeta. Neste sentido, ressalta um perfil histórico parecido em alguns traços com o gentleman e que carrega em si a condição de florescer na pobreza: o Hidalgo. $\mathrm{O}$ Hidalgo se aproxima do gentleman na dimensão de dignidade que dá a sua existência. Ao mesmo tempo se afasta dele pelo fato de não trabalhar e, como consequência, não cria técnicas. 


\subsection{A coisa e o seu ser}

De posse das exemplificações dadas anteriormente, Ortega segue o curso tratando agora da coisa e o seu ser. Para identificarmos algo como coisa é necessário recorrermos a sua forma tal como está funcionando, pois se isolássemos os ingredientes que forma tal coisa não a constituiríamos como a coisa. Exemplo: para que vejamos a água é preciso que desapareça o hidrogênio e o oxigênio. A definição de coisa a partir da enumeração de seus ingredientes se converte a alguma coisa como a pré-coisa, ou seja, o ser da coisa. E só se conhece bem alguma coisa quando se vê nascer, por isso a necessidade de se buscar a pré-coisa. O único ente vivo capaz de formular o projeto de vida através da imaginação é o homem. Insere-se nesse projeto a técnica. Mas, não basta o homem possuir inteligência técnica para que ela exista. Faz-se necessário o exercício efetivo dessa capacidade. Nesse sentido, o que diferencia o homem do animal não está na diferença entre seus mecanismos psíquicos, mas nos resultados que ela traz consigo. Assim, somente num ente em que a inteligência está a serviço da imaginação criadora de projetos de vida faz sentido em falar de capacidade técnica. Ortega destaca que a técnica do seu tempo chegou a um lugar que nunca tivera. Podemos perceber isto contrapondo com a idade paleolítica apresentada no filme A guerra do fogo, onde naquele tempo ainda se descobria o fogo e o domínio do mesmo. Já na época da escrita de Ortega a relação entre o homem e a técnica se elevou a uma potência peculiar e essa elevação somente pode se dar pela modificação substancial da própria função técnica.

\subsection{Os estágios da Técnica}

A seguir, Ortega apresenta três estágios da técnica, a saber: a técnica do acaso, a técnica do artesão e a técnica do técnico. No primeiro estágio a técnica está presente na vida do homem primitivo, mas é como se ela não estivesse. $\mathrm{O}$ homem ignora a existência de sua própria técnica, não percebendo que dentre suas capacidades existe à de reformar a natureza para estabelecer seus desejos. Ele acha que pode produzir fogo da mesma forma que pode andar. Ele não sabe que pode inventar e, por conta disso, não busca soluções. Mas, são as soluções que o buscam, pois é a natureza a responsável pelas invenções. É o manejo desenfreado das coisas que faz o homem primitivo produzir, por conta do acaso, um novo e útil resultado. O segundo estágio é a técnica praticada na velha Grécia, na Roma pré-imperial e na Idade Média. Nesse estágio se tem uma crescente dos atos técnicos, quando comparado à técnica do acaso. Muitos desses atos se fizeram tão complexos que nem todos conseguiam 
exercê-los. Cabia, então, ao artesão a dedicação em conhecê-los a fundo. Nesse estágio já se tem uma consciência do valor da técnica, porém ela é assumida pelo homem como um atributo natural. As técnicas são chamadas por estes povos como um sistema fixo das artes, onde se encontra o homem situado, assim como fixos são os movimentos de seu corpo. Sabese também, neste estágio, que a técnica é concernente ao homem e não ao animal e que, naquele tempo, não se concebia a consciência do invento no artesanato - era a época dos grandes aprendizados pelos mestres. No terceiro estágio o homem já detém a consciência de que possui certas capacidades distintas das rígidas que integram sua porção natural ou animal. A técnica não é um acaso e nem um limitado tipo de homem - artesão, mas um conjunto, a princípio ilimitado, de atividades humanas. A consciência de ser ilimitado possibilita ao homem a construção de máquinas e não apenas ferramenta; e também denota a ele, em princípio, a capacidade de ser o que lhe for imaginável, deixando, contudo, de saber o que efetivamente é.

Hoje o homem já está preso à sobrenatureza e colocado na natureza de modo que não há possibilidade de escolha. Um dos riscos disso é o homem considerar que tudo que está disposto a ele está aí por si mesmo. E, com isso, perder a consciência da técnica. O próprio crescimento desta ameaça escurecer tal consciência. Hoje o técnico se dedica, como uma atividade normal, à invenção. Diferentemente dos primitivos, conforme mostra o filme $A$ guerra do fogo, cujo ato de inventar não constituía um ofício, dado que o homem ignorava seu próprio poder de invenção que, no caso, a produção do fogo na Idade Paleolítica. Cabe destacar ainda que não existe técnica sem tecnicismo - método intelectual que se opera na criação da técnica. O tecnicismo é necessário, mas não suficiente para a técnica. Ele é bem

diferente hoje do tecnicismo utilizado nas técnicas passadas. É no século XVI que há o crescimento do novo tecnicismo e a vinculação da técnica à ciência, constituindo método intelectual. Isso dá independência e segurança em si mesma à técnica moderna.

\section{Fim das notas apresentadas}

Ortega conclui dizendo que convém ao intelectual manejar suas coisas; se é físico: maneje as coisas materiais, se é historiador: maneje as coisas humanas. Todos os historiadores perceberam ciência e técnica sendo da mesma natureza e, desde então, o seu desenvolvimento foi fabuloso. Por fim, ressalta que a vida humana não é somente a luta com a matéria, mas 
também é a luta do homem com sua alma. E compartilha com o leitor o sonho da existência de um curso que apresente frente a frente técnicas do Ocidente com as técnicas da Ásia.

\section{Referências}

A Guerra do Fogo (La Guerre du Feu). (1981). Aventura, França/Canadá, 97 min, COR. Direção: Jean-Jacques Annaud.

Ortega Y Gasset, José. (1963). Meditação da técnica. Rio de Janeiro: Livro Ibero-Americano.

Ortega Y Gasset, José. (2009). Meditações sobre a técnica. Lisboa: Sociedade Unipessoal.

\section{Porcentagem de contribuição de cada autor no manuscrito}

Eduardo dos Santos de Oliveira Braga - 50\%

Valéria da Silva Lima - 50\% 